\title{
Pancreatic Gastrinoma
}

National Cancer Institute

\section{Source}

National Cancer Institute. Pancreatic Gastrinoma. NCI Thesaurus. Code C95596.

A neuroendocrine tumor arising from the pancreas. It is characterized by inappropriate secretion of gastrin and associated with Zollinger Ellison syndrome. The latter is characterized by the presence of peptic ulcer, gastroesophageal reflux disease, abdominal pain, diarrhea, and malabsorption. 